\title{
Cognition is Recognition: Literary Knowledge and Textual "Face"
}

\section{Citation}

James Simpson. 2013. "Cognition is Recognition: Literary Knowledge and Textual "Face"." New Literary History 44 (1): 25-44.

\section{Published Version}

http://muse.jhu.edu/journals/new_literary_history/v044/44.1.simpson.html\#back

\section{Permanent link}

http://nrs.harvard.edu/urn-3:HUL.InstRepos:12872088

\section{Terms of Use}

This article was downloaded from Harvard University's DASH repository, and is made available under the terms and conditions applicable to Other Posted Material, as set forth at http:// nrs.harvard.edu/urn-3:HUL.InstRepos:dash.current.terms-of-use\#LAA

\section{Share Your Story}

The Harvard community has made this article openly available.

Please share how this access benefits you. Submit a story.

\section{Accessibility}




\title{
Cognition is Recognition: Literary Knowledge and Textual "Face"
}

\author{
James Simpson
}

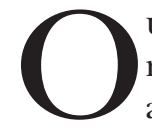

UR LANGUAGE FOR THE TRUTHS OF LITERATURE is reformist and nominalist; our experience of reading is, by contrast, habitual and idealist. Contrary to the way critics talk about what kind of new, liberatory truths literature expresses, our actual reading practice is grounded in long-standing forms of recognition. Every time we interpret we recall deep-seated, ingrained, and circular protocols that give us access to truths immanent within the separate realms of literary experience. As interpreters, we depend on préjugés that produce recognition of already existing truths.

Such, at any rate, is the thesis of this essay. That literary knowledge is thus Janus-faced, looking resolutely forward even as it draws deep on a backward gaze, is in no way contradictory or disabling. The deepest posture of Anglo-American literary pedagogy is grounded, rightly, on the conviction that literature liberates. We prize what is new, what destabilizes the solidities of official culture, and what points to liberation from the strictures of the norm. We also prize the individuality of each work, partly because we prize individuality and partly because we need the business: as long as each work, and, more recently, each material text of each work, is distinct, there's work in it for us. The current essay is in no way designed to undo these Enlightenment-derived convictions about liberation from the past or to question these perfectly reasonable business necessities.

I am, however, concerned to show that our reading practice is differently grounded, on opposed premises. Our reading practice, that is, depends on deeply instilled norms and begins by assuming that every work in a certain genre is the "same" work, a work that we "knew" before we began reading the "new" work. Literary knowledge, that is, is dependent on recognition. We know because we knew. Literary cognition is fundamentally a matter of re-cognition.

This default position for reading is certainly at odds with any revolutionary pedagogic program that prizes originality and pure novelty, wholly freed from the strictures of the past. The default practice of 
"recognitional" reading proposed here is not, however, at odds with a reformist and a nominalist interpretation of a work, since the recognitions of literary experience are not instances of mere repetition; on the contrary, the literary recognitions we care about are memorable because we see a truth-we know the place, we see a face-as for the first time, and as unique. The recognition is old and general; the force of the recognition is reformist and very particular. When Dante first sees Beatrice at the summit of purgatory, at the very moment he must abandon Virgil as a guide, he makes a recognition both personal and literary: "cognosco i segni del'antica fiamma" (Purgatorio 30.48), ${ }^{1}$ he declares, citing Dido's "agnosco veteris vestigia flammae" (Aeneid 4.23). ${ }^{2}$ Dante's recognition is expressed in terms of the old, the dying, and the universally available; the force of that recognition is, by contrast, powerfully revivifying, painfully reformist, and unique to Dante. ${ }^{3}$

The old, the dying, and the general are, that is, the very conditions of the revivification, the reform, and the unique application. An abiding literary canon is never therefore obsolete, since it remains fresh for every generation of new readers. Informed conversation with a recognized past, central to the entire tradition of liberal education since antiquity, is the condition of reformist movement into the future.

My case is clearly about the practice of literary reading itself. I begin, nonetheless, with a literary example in which represented recognitions occupy a very high profile. I begin thus precisely in order to give a strong instance of why revolutionaries (as distinct from reformists) might not prize recognition. I start with scenes of recognition in a short English romance of the early fourteenth-century, Sir Orfeo. Such scenes are grist for the mill of those who would dismiss recognition as the sign of the manipulatively ideological old order. Such dismissal resisted, I go on to use this narrative example to craft a model for interpretive recognition.

The early fourteenth-century romance known as Sir Orfeo narrates the story of Pluto's capture, and Orfeo's recuperation, of Orfeo's queen Eurydice. Asleep under a fruit tree one May day at noon, Eurydice wakens and lacerates herself, having been told in her sleep that she will be collected the following day and taken to the underworld kingdom of Pluto. That day having come, Eurydice vanishes from within a protective military guard. Orfeo immediately renounces his crown, appoints his steward as king, and quits his kingdom, sparely dressed and equipped only with his harp. For ten years he lives, winter and summer, unprotected 
in the forest, providing solace with his harp to animals alone. Often he observes the train of Pluto the king of Faerie, but one day in particular he follows a group of "faerie" women as they dance in the forest. He and his wife recognize each other: Orfeo "yerne [penetratingly] beheld hire and she him eke / But neither to other a word ne speke" (323-34). ${ }^{4}$

They separate for a second time, but Orfeo follows the troop through a rock into a splendid underworld at whose center stands an intricate, brilliant castle. Orfeo gains entry by promising to harp for the court, but once admitted, sees the paralyzed inhabitants of the castle, all in fixed postures and many disabled, along with many wives captured as they slept at noon. Amongst these women he recognizes his own wife. Orfeo performs beautifully on his harp before the court of Pluto, who, deeply touched by his playing, offers whatever gift the minstrel should choose. Orfeo requests the gift of Eurydice, but is denied by Pluto on the grounds of the disparity of his ugliness and Eurydice's beauty. A thing yet more ugly, Orfeo replies, would be a promise broken by the king. Pluto recognizes the force of this argument and delivers Eurydice.

Returned to his own city, Orfeo leaves his wife in the poor cottage where he had taken refuge, and enters the city in disguise as a beggar minstrel. He is received by the steward and permitted to play before the court. The steward recognizes Orfeo's harp; he weeps profusely on hearing from the unrecognized Orfeo that the harp was found in the forest ten years ago, beside a dead man lacerated by lions. On seeing the steward's tears for the imagined loss of Orfeo, the beggarly minstrel declares that if he were in fact King Orfeo returned, he would recognize the fidelity of his steward and nominate him as successor. At this point all recognize their king returned ("alle tho that therinne sete / That this was Orfeo underyete [understood]" [lines 579-80]). The steward pushes the table over and falls at Orfeo's feet. Orfeo is washed and shaven. Eurydice is fetched from the outskirts of the town, and they reappear as king and queen, accompanied by much minstrelsy, to live happily ever after.

So ends the faery story, with an ending that reconfirms the traditional order: a marriage on whose solidarity depends the political order. Recognitions are crucial to the narrative outcome: Orfeo and Eurydice silently recognize each other; Pluto metaphorically recognizes the force of his word; and the steward recognizes first the harp, and then Orfeo himself. Recognitions are the articulations of the narrative, the moments where the centrifugal energies of a romance narrative are turned back upon themselves to lead centripetally homeward. By the end of the narrative, thanks to these recognitions, everyone is back where they ought rightfully to be by "nature," in their "proper" place. 
The conservative happiness of this ending is precisely what has raised hackles of many stripes against stories of this kind. The political revolutionary will reject the affirmation of the old order; and those traditions, both religious and secular, that identify self-knowledge with crisis and alienation will also reject the representation of identity wholly recovered. This story conserves the social order by bringing everyone back home: Orfeo as king, Eurydice as his wife, and the faithful steward as trusty subaltern. Even, or rather especially, Pluto, King of the Underworld, is brought within the tale's civilized pale. The intense emotional foci of such stories, it could be objected, underwrite an order of "nature" that is simultaneously self-serving, conservative, and naïve. The young hero does not so much develop in these stories as show his already-formed nature; this is a demonstrative story whose most obvious narrative motif of aventure, or chance, is in fact a decoy: the aristocratic protagonist must always win, by virtue of his genes in a providential universe. Narrative is driven most deeply by commitment to nobility of blood, which will show through. In order to disguise and defer that inevitable, genetically programmed demonstration, the narrative gives very high profile to disguise, chance and deferral. It does so precisely because there is no permanent disguise, no real chance and no sustainable deferral in this story. The narrative must end happily with the anagnorisis of identity and a societal structure reconfirmed upon that recognition.

A reading that dismisses the recognitions of Orfeo as at best sentimental escapist fantasy or at worst as ideologically manipulative (or both) strikes me as reductive. The text does indeed reaffirm the "civilized" order, and that order is aristocratic. In fact, however, the social ideology of Sir Orfeo is more complex and richer.

True, the very circular shape of such a story, returning to beginnings as it does, would seem conservative. The entropic catastrophes of history are held at bay. Everything ends just as it had begun. Despite appearances, however, the ending is not the same as the beginning: the key personal and political relations have now been tested.

True, the identity of Orfeo is reaffirmed. That identity is, however, reaffirmed only by virtue of Orfeo being prepared to abandon it unconditionally, and for what turns out to be a sustained, ten-year period of isolation and alienation.

True, the narrative is focused on the single aristocratic male. But narratives of this kind will always delineate the alliances that the central male needs to return to the locus of power. These alliances (here with the steward, with Pluto, and with Eurydice) reveal the dependencies of the aristocratic male. Often that dependency will reveal identities of nature and interest between categories otherwise presented as binary opposites, 
such as, here, the worldly king and the king of the other world: both recognize the rule of fidelity, and both are susceptible to the irrational yet civilizing power of music, along with forest beasts.

And true, this narrative represents the male saving the woman, confirming the common view of romance plots as stories of knights saving damsels in distress. But that motif is a decoy here: it's rather the damsel who, with her silent gaze of recognition, saves the knight.

So a particular version of the civilized order is indeed reaffirmed at the end, but that civilized order has been enlarged and reformed by underlining its dependency on, or subjection to, all that threatens it. At the end of this narrative we might remember a detail we were told at the very beginning (line 29): that Pluto is Orfeo's grandfather. The civilized order has been reaffirmed by revealing the full extent of its dependencies and surprising genealogies. That order has also been reaffirmed from within its inherent social and psychological resources, not imposed from above by legal coercion. These are stories whose conservatism is reformist.

Such stories express, indeed, a deeper wisdom: that for the "civilized" order to maintain its balance, it must have commerce with, and enter into, everything that threatens it. Mere resistance only more acutely exposes vulnerability. Such narratives can be said to be cybernetic, in the proper sense of "self-governing": they model how societies can maintain their balance only by entering into all that challenges them, when that entry into the wild seems to promise nothing but oblivion. They are not fundamentally about ethics, but rather about the ecology of wild and civilized that must pertain before we can begin to talk about ethics. There is no analytic consciousness articulating the truths of narrative; neither is style significant, since story structure does all the work, and that story structure is designed to model the ideal structure of civilization.

The key articulations of this cybernetic narrative are, as I have said, moments of recognition. So, far from those moments marking mere repetition, they are instead moments that open onto a future, and that lead back home. They also reaffirm the social structure where that structure is most completely integrated, as psychological, political, and ecological systems interlock. The recognitions are marked by intense emotion: the couple gazes silently, knowingly, and "yerne" (avidly) at each other in hostile territory; the steward knocks the table over in his eagerness to embrace his recovered lord. Recognition moments are marked not only by intense emotion, but also by complete cognitive understanding of a situation: the couple knowingly need say nothing, and the court "that this was Orfeo underyete [understood]." In these moments of recognition, emotion and cognition themselves interlock at high pitch. 
In sum, to dismiss such apparently simple stories as either naïve or "conservative" is to dismiss a great deal. It is, indeed, to miss a great deal, since the simplicity is deceptive, and the conservatism by no means inert. The story is reformist rather than reactionary; through recognition, it opens back onto, and reinvigorates, a desired and recuperable world. Regardless of whether or not the reader is sympathetic to such represented recognitions, the deeper point, to which I now turn, is this: the experience of reading such stories by their own grain is itself dependent on recognition. ${ }^{5}$ As we read, we are always looking for the familiar face or feature, or topos (that is, commonplace) from the past. To read this or any work well, we need to understand how such works operate, what kinds of meaning they habitually offer, and what kinds of meaning they habitually do not offer. We need, it might be said, to recognize their "face." We need, in short, to understand the workings of genre.

Middle English scholarship eschews generic or modal clarity with regard to stories of this kind. ${ }^{6}$ After having remarked on the difficulty of defining the genre of romance, one scholar, for example, says that "any comprehensive survey should allow the reader freedom to form his own impression of the range and variety of English romance without imposing on the corpus preconceptions of how mode ought ideally to be embodied or what constitute the essential characteristics of the genre." This is good liberal encouragement to keep an open mind, in freedom, without prejudice, free of habit. Unfortunately, however, interpretation cannot successfully survive free of habit, since any hermeneutic act itself depends on préjugés; without assumptions about the kinds of meaning available in a work, or at least about what kinds of meaning we are looking for, we cannot even begin to make sense of what its precise meaning is. ${ }^{8}$ An artifact implies its history, and is illegible without habituated understanding of that history. Genre illuminates the present operations of a text by casting light on textual topoi (or commonplaces) we are habituated to recognize from past texts.

Eschewal of hermeneutic habit fails to understand fundamental hermeneutic necessities: before, that is, we can understand the meaning of any communicative act, we need to understand what kinds of meaning are likely to be available in that kind of communicative act. We need to know about the communicative act before we decode it, precisely in order that we can see the text's "face," or recognize it. This kind of cognition implies, paradoxically, recognition. We need, that is, to recognize the kind or type or genre of the communicative act before we can begin to understand what meanings are likely to be available in that act, let 
alone what the precise meanings of the act are. So far from it being the case that presuppositions, habits, and préjugés are to be distrusted, our perception cannot begin to operate without them. This applies to the decoding of any local trope, as much as it applies to the global recognition of genre.

In what remains of this section, I briefly offer graded rhetorical examples, from local to global, designed to demonstrate that we generate meaning through habitual recognitions. ${ }^{9}$ These examples are not restricted to the genre of romance, but each is designed to underline this point: without recognition of textual features drawn from our textual experience, we understand very little. The words on the page do not themselves offer up their meaning. We as readers need, rather, to supply our presuppositions about the text to make it leap into life, and we supply those presuppositions by recognizing what kind of text it is. Absent our effort to perceive unstated meaning, and to suppose intended meaning, all verbal signs, literary or not, remain forever cut off, floating helplessly as disiuncta membra in a world of perpetual unreadability. The words on the page, or in the conversation, do not state their meaning; we need to enter a circle, via recognition of general kind, before we can begin to interpret specificity.

I start with a single metaphor. Take Donne's "No Man is an Iland, intire of itselfe." ${ }^{10}$ Taken literally, this statement is true but uninformative: no man is, indeed, an island. The simple point of the statement is only perceived if we recognize the word "island" as a metaphor. And this simple recognition is only possible if we allow ourselves to infer an unspoken meaning standing behind and before the text. We do this on an ethical impulse, since we assume (i) that Donne is not insane; and (ii) that he must mean more than he says, since he wouldn't waste our time with uninformative statements, and neither would he discuss islands in a meditation. Our recognition of the metaphor proves Donne's point by soldering our relation with Donne (d. 1631) himself: we prove, once again, that no man is, indeed, an island. We assume that Donne's statement has what the philosopher and protopragmatist H. P. Grice called "implicature," which is to say, logically unmotivated implications. ${ }^{11}$ Before we pass on from this example, we should also note that it's we who decide whether or not the statement is metaphorical; there is no such thing as definitively denotative or metaphorical language: we decide, according to context, whether a communicative act is denotative or not.

My second example is that of irony. In classical and medieval rhetoric, irony is a subset of allegory: allegory "says one thing and means another"; irony "says one thing and means its opposite." When we look to irony, we see the same necessity to recognize an originating intention outside and 
prior to the text. Swift's Modest Proposal (1729) argues that Irish babies be sold as food, thus simultaneously solving the problems of both famine and overpopulation. Swift's "words on the page" will certainly make us acutely uneasy, but in themselves, taken literally, they mean only what they say. The peculiar mixture of social delicacy, rational argument, and blind viciousness in the Proposal creates unbearable strains for a reader committed to a literalist reading. As soon, of course, as we posit and then recognize an unspoken, ironic strategy, that strain is transformed into relief of sorts, as we recognize the civilized "face" of the text.

With what justification do we posit that the author "means the opposite" of what he says? We can only do so by first positing, then testing the force of, an informing yet unstated meaning. We are emboldened to posit that unstated meaning, in whose light we recognize textual meaning, from our experience of satire. Once we see how effective that strategy would be, we tend to accept it. It's our identification of the unstated meaning generating the text that transforms what the words mean into what the author meant by them. The bizarre locutionary force of the words (what they say literally) is transformed into a believable strategy by recognition of their illocutionary force (what we take the author to intend by them). ${ }^{12}$

We actively participate in the construction of meaning by trying to recognize the strategy behind words. Even if we identify that strategy wholly from within the text, with no reference outside it, we still, conceptually at least, posit that strategy, or intention, as logically prior to, and therefore outside, the text. We are obliged, paradoxically, to enter (not to break out of) a circle when we interpret. We are obliged, that is, to lead back to intentions on the basis of meanings that have been accounted for by those very intentions. We need to recognize, to lead back to hermeneutic home after a period of alienation in a forest of hermeneutic uncertainty; our own moment of recognition is marked by that pleasurable interlock of heightened emotion and cognition. Some of us might dismiss romance plots as ideological, but the plot of our reading itself follows the trace of a romance plot.

Having looked at two tropes (metaphor and irony), let me return to Sir Orfeo by way of showing how understanding a whole text via genre is a matter, too, of recognition.

Perception of a genre will involve a flexible combination of a variety of literary features: works that share a certain purpose, a certain subject matter, a certain length, a certain style and structure, and a certain point of view will be said to belong to a certain genre. Depending on the genre, the combinations and the presence of any one of these features will be more or less significant for generic understanding. ${ }^{13}$ 
Orfeo is a romance. Stories of this kind share the following characteristics. They have a tripartite story structure: a state of integration, or implied integration, gives way to a state of disintegration, successfully undergoing the trials of which is the premise of reintegration. The reintegration of the protagonist extends to the story itself: all the apparent chances of the story play their part in propelling the protagonist back to his or her "proper" place. Every episode plays its part; for this reason story structures are nested, or chiastic, moving through a sequence of clearly delineated episodes until the protagonist is most lost and dislocated, before moving back through that same sequence as the protagonist recovers his or her identity. These stories end happily. That which is lost is found. The logic of their episodic structure is driven by the logic of the ending: the structure carefully defines what events, in what order, are necessary to achieve that happy ending.

Such narratives evoke the irreparable disintegrations of tragedy only to evade them, often by near misses. Orfeo explicitly invokes tragedy by close, provisional resemblance with its more famous and powerful tragic twin, in which Orpheus looks back to lose Eurydice forever. The narrative content of these stories is driven by archetypal binary oppositions: for example, male versus female, human versus monster, castle versus forest, and (the master opposition) nurture versus nature. The civilized order, represented for the most part by the young, enters into all that threatens it and discovers that, by drawing on the resources of the civilized order, the apparently insuperable forces of the wild can in fact be managed and absorbed. By undergoing and overcoming the tests of the wild, the young regain the site of reintegration, having recouped the losses of history, and having set the entropic forces of history at bay, ever after.

Our knowledge of the way these stories habitually work informs our reading of this one. We recognize features of the story at hand because we know many such stories and read each as if it were, at first at any rate, the same story. Our préjugés about how such stories work points us to certain features in which we recognize how this particular story is working. We turn our attention to one set of variable possibilities and away from many others. In Orfeo we do not, that is, expect or look for the societal catastrophes of tragedy; the irredeemable personal losses of elegy; or the mordant laughter of satire. The concept of genre encodes and compacts a tightly bound, exceptionally generative nexus of subconcepts. Recognition of salient, persuasive meaning always involves rescue from the potentially random and infinite play of signifiers. Alreadyexisting knowledge of how genre works produces that recognition, since it points us to textual features that have already, many times, worked to produce deeply meaningful communicative acts, before we read this 
act. By those known features we recognize the salient "face" of this act. Orfeo recognizes Eurydice; we recognize Sir Orfeo.

Recognition of the "face" of a text is often sudden in its transformative illumination. To be sure, many separate figures of speech in a text point us backward: the very etymology of "verse" turns us backwards, just as rhyme, alliteration, anaphora. and chiasmus are, for example, all figures of repetition, turning us back even as we move forward. Literary appositional syntax, no less than the narrative structure of starting in the middle of the narrative before we move back to its origin, no less than literary allusion itself, takes us backwards as we move forwards. Each invites cognition through recognition, each offers forms of recapitulation. Our recognition of genre might involve analytical observation of these figures and features separately, but the moment of generic recognition, which is simultaneously the moment in which we recognize the individuality of a text, tends to be a moment: it is sudden, synthetic, transformative, and pleasurable rather than incremental, analytic, sequential, and arduous.

We can only learn the rules of the generic game by playing particular instances of the game. Such a position is also circular: we play the game by the rules, but we learn the rules by playing the game. That interpretive logic should be circular is, in itself, no objection whatsoever, since all hermeneutic activity is circular: we must work within hermeneutic circles, within which we understand, for example, the whole from the parts and the parts from the whole, the rules from the details, and the details from the rules. ${ }^{14}$ Of course we can make mistaken recognitions of a text's "face," but by playing the game repeatedly, we become better players. That generic mixing and nesting should be predominant in one period (for example, the medieval) as distinct from the fastidious generic clarity in another (for example, the eighteenth century) is a matter of deep significance for cultural history. But all periods will need to observe generic stability in one way or another, since interpretive understanding, recognizing the "face" of a text, cannot operate without it.

Such a persuasion should be fundamental to all humanistic activity, but especially to understanding of artifacts, whether literary, visual, or musical, for example, since the arts are more explicit about their need for interpretation, and, therefore, about generic indebtedness and exploitation. However much they may be susceptible of interpretation, neither natural phenomena nor much human behavior demands interpretation. Expressive artifacts, by contrast, necessarily do communicate and therefore call forth interpreters. Without an understanding of genre, without recognition, we remain unable to answer that call.

Knowledge derived through recognition is distinctive, insofar as it assumes preexistence. Unlike the triumphant discoveries by science of 
the never-before-known, the recoveries of literary understanding are not original; on the contrary, we register them, afresh, as recoveries of what has been known and then partially, or totally, forgotten. They are like the "finds" of etymology, sudden illuminations of immanent truths that reconnect us with a long-forgotten, or at least alternative, way of thinking. The meeting of the preexistent in fresh circumstance is so overwhelming, in its force and pleasure, that it renews the already known, making "her old face new." They produce the "Qual maraviglia!" of Dante's teacher now in hell, as he peers through the darkness, as under a new moon, to recognize his former pupil. That former pupil Dante, in turn, looks with such penetration through the "cotto aspetto" of his teacher so that he, too, recognizes and names Ser Brunetto (Inferno 15.18-30).

The surprise of this kind of literary understanding, like Brunetto Latini's surprise at recognizing his former student, is never one of astonishment at the wholly new. It is, instead, more like astonishment at the wholly surprising old; it is more like greeting a long lost parent or child or friend or lover or teacher or student—what you will—and being captured by wonder at the force of the recognition in new circumstances, as under the new moon. The knowledge produced by recognition is an invention in the older sense of the word (Latin invenire), a find rather than a discovery in the modern sense. It works on the assumption that knowledge (of this kind, at any rate) is immanent (Latin "in-manere," to remain within), buried beneath the "cotto aspetto," rather than discovered outside the pale of the previously known.

Recognition-derived perception does not, that is, provide original experience. It is not revolutionary. On the contrary, its recoveries radiate the exquisite pleasure of knowledge that illuminates precisely because it is not original. It offers deeply illuminating repetition in fresh circumstance. The illuminating truth of artistic history is embedded within history, not discovered from outside. The interpreter's pleasure is perhaps comparable to the archaeologist's: every work is a find, packed with histories just waiting to be revivified. Behind, or within, the literary text lie the treasures of the past, treasures by whose gleam, as under a new moon, we suddenly see our present condition afresh. Much knowledge produced by the humanities would by definition have been unavailable to its historical actors. For the knowledge that would by definition be available to its historical actors, recognition provides a compact model.

\section{III}

The phenomenon of cognition through recognition is not, however, in any way restricted to literary understanding. It is instead rooted in 
our broader linguistic and perceptual habits. "Implicature," which in good part generated the branch of linguistics known as pragmatism, points to that area of meaning beyond the reach of semantics. "Where's Bill?" someone might ask, to which the response might be "There's a yellow VW outside Sue's house."15 The semantic content of the reply offers no response to the question; on the face of it, and by a literalist reading, the response is irrelevant to the question. We make these two statements a part of a single narrative, however, on the assumption that the respondent is in fact answering the question. The very appearance of irrelevance provokes us to hypothesize, and to recognize, relevance at a further level. We infer many things, in fact: that the respondent is sane; that the answer is relevant; that the car had transported Bill; and that Bill is at Sue's house. None of these inferences is logically generated. They are, on the contrary, inferred simply from an expectation of conversational relevance.

Relevance is one of Grice's four principal maxims of conversation, all of which are contained under a general principle of cooperation. The other three are quality (do not lie), quantity (offer only as much information as the exchange requires), and manner (avoid obscurity or ambiguity, and preserve a chronological order of narration). Readers familiar with classical and medieval poetic treatises will be amused at these maxims, since those treatises encouraged writers to break almost each one of them. Grice, however, absorbs literary language by showing how flouting the maxims continues to produce inferred meaning. These inferences are testimony to the "remarkable robustness of the assumption of co-operation: if someone drastically and dramatically deviates from maxim-type behavior, then his utterances are still read as underlyingly co-operative if this is at all possible."16 Donne's "no man is an island" flouts the maxim of relevance to observe with especial force the maxim of quantity, offering a great deal of information in a very short space.

It might be objected that the literary examples discussed in the previous section are rather special cases, and that a good deal of everyday language is fairly clear, unambiguous, and self-sufficient. I don't think this is true at all. Grice generated his theory of "implicature" out of the practice of conversation; he reveals that any conversational exchange relies on a complex and dense exchange of implicatures surrounding the semantic content of the conversation. Consider the following conversation between me and my daughter age six. She holds in her hand a red, wooden elephant. The conversation follows thus:

Father: What is it?

Daughter: It's red.

Father: Yes, but what is it? 
Daughter: It's wooden.

Father: Yes, but what is it?

Daughter: It's a gift.

Father (now fascinated): Yes, but what is it?

Daughter: It's an elephant.

I found this exchange both funny and illuminating, precisely because my daughter's unwitting flouting of the rules of conversation revealed to me how arbitrary those rules are. Needless to say, I expected the answer "elephant" to my first question; what I received instead was a series of true statements, each of which understood "is" to denote an entirely different quality of the object. Because my daughter had not been habituated into the conceptual hierarchy whereby we give priority to thing denoted, she used the word "is" more literally than would have been the case had she answered my question as first expected. That is to say, the wooden toy was in fact more accurately described as red, wooden, and a gift than as an elephant. My daughter "failed" to recognize a preexistent consensus concerning the word "is," and so "failed" to recognize what kind of conversation I expected of her. She had clearly absorbed three of Grice's maxims (quality, quantity, and manner), but not entirely the fourth, relevance. She could only have absorbed this maxim by practice, since its application is purely arbitrary.

An example such as this challenges any easy separation of literary and ordinary language on the grounds of complexity. ${ }^{17}$ How, all our linguistic examples (both literary and "ordinary") demand of us, do we get from what a statement means to what a speaker or writer means by it? Within any text (however one understands that term) we need to interpret the part by the whole, and the whole by the part, and we account for meanings of both parts and whole on the basis of evidence whose meanings we have already inferred from both parts and whole. In all communicative situations our hermeneutic thinking is circular; we posit a face of the communicative act in order to recognize its meaning.

Neither is such an account of perception limited to verbal perception. All our senses organize and make sense of the world through recognitions. This is clearly a huge topic, so let one beautifully succinct example suffice to point us towards our broader perceptual habits:

The key features of our psychological response to this amusing and classic image are as follows: we cannot see lively duck and humble rabbit simultaneously; it's we who decide what to see; and, as we decide what to see on the basis of our own, produced recognition of duck or rabbit, we organize our perception differently. ${ }^{18}$ The eye remains an eye as the focus of our recognition, but every other principal mark serves different purposes according to the viewer's decision. Rabbit's ears become 


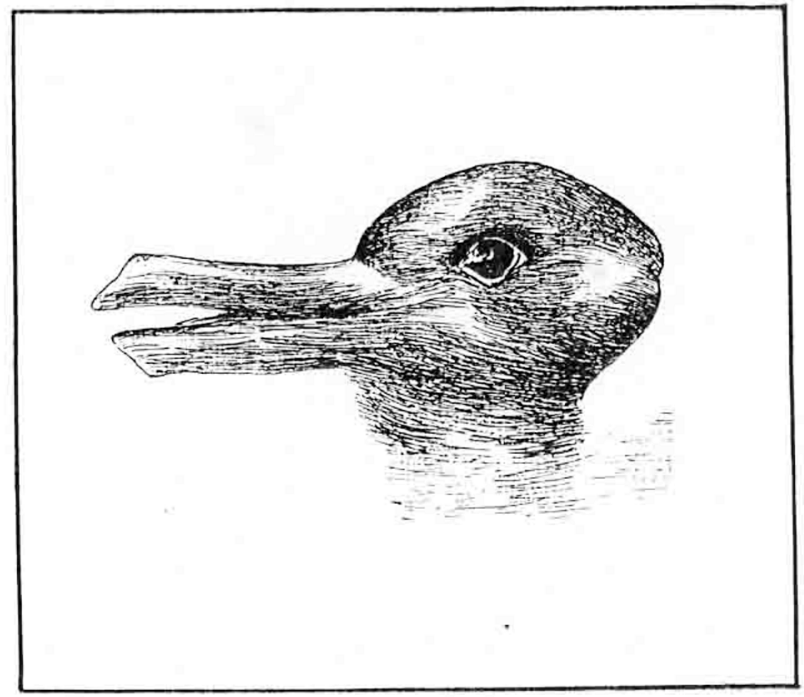

Fig. 1.

duck's beak according to what we decide to recognize, and what features we decide to demote. ${ }^{19}$ We also experience this same psychological phenomenon whenever we unsuccessfully look for something with the wrong mental image: if we look for the book with the green spine using the mistaken mental image that the spine in question is blue, we can "see" the green-spined book any number of times without recognizing that this is the book for which we are in fact looking. We truly see only what we recognize. As for machines taught face and voice recognition, so too for humans: perception is preception.

Recognition, then, characterizes literary interpretation no less than the very much wider fields of linguistic and sense-derived interpretation generally. Despite that fact, at least three influential discursive fields in Western culture must, with powerful reason, maintain the fiction that recognition has no part to play in reading and perception. These fields must maintain the fiction of positivism, that the real world datum comes first and that the real world datum is the only source of truth, from which follows understanding. Such powerful currents, which are understood as the default, common-sense position of our society, must therefore continue to describe the action of interpretive recognition pejoratively, as prejudice.

Those three fields are as follows: Protestant biblical interpretation; scientific enquiry; and constitutional interpretation in revolutionary societies grounded on a written constitution. Each of these fields must 
strictly deny that an interpreter should recognize the truths of the object of enquiry by positing logically unmotivated meanings. Each field must instead posit (in the textual examples) that the entire meaning of a text is contained in its words, or (in the case of science) that the entire meaning of a natural object derives from the object itself. Such fields therefore maintain that we should restrict ourselves to those meanings derived wholly from the words on the page, or from the object under enquiry. To engage dialectically in the production of meaning is, for each of these traditions, to exercise prejudice. Each will also, not coincidentally, actively posit that there is such a thing as the literal sense, and each will repudiate figural, or tropical, language of any kind.

Positivist traditions will surface within particular historical environments. The most powerful historical environment is, in my view, the sixteenth-century Protestant Reformation, for which text's absolute priority to institution was a nonnegotiable necessity. For sixteenth-century evangelical polemicists, Scripture had to precede Church, since it was Scriptural authority that determined the Church, rather than the other way around. Scripture, therefore, had to be both incontrovertible and straightforward. Scripture had also, therefore, to be literal. The existence of figurative language (for example, allegory) implied the need for an expert body of readers with understanding of how to recognize the meaning of the text in ways not explicitly directed by the text. ${ }^{20}$

The Scientific Revolution that began in the seventeenth century posited that things and ideas were absolutely prior to words, and that words should be tailored in strict, denotational subservience to those things and ideas, avoiding all figural language whatsoever. ${ }^{21}$

And the late eighteenth-century revolutionary societies (the United States and France, for example) imagined that they were brought into being by constitutional documents. Text was, therefore, absolutely prior to communal understandings of text, and text is therefore to be understood without prior experience of the protocols within which that text was produced. The truths of text are held to be self-evident; text brings society into being, rather than the other way around. And text is to be shorn of figural language.

The psychological correlative of all these revolutionary cultures is an empiricist account of the psyche as a blank slate on which the world is impressed and thereafter understood. Both history and the psyche start from scratch.

The default positions, textual and psychological, of revolutionary societies will label preexistent persuasions about meaning as prejudice. They will actively repudiate the preexistent ideas of both Platonism and one of its derivatives, late antique Christianity, for both of which recollection (and, therefore, recognition) was cardinal, as idealist mystification. ${ }^{22}$ 
Psychological empiricism will also repudiate figural language, since decoding metaphor or irony (for example) presupposes presupposition.

Textual positivism and its correlative, psychological empiricism, might seem to avoid the strongest rational objection to the account of recollective, recognitional interpretation given above. It might seem, that is, to void the objection that such interpretation is circular. The meaning arrived at when we decode figural language or genre is, as we have seen, the one that generated the interpretative process in the first place. Or, to put it slightly less baldly, we generate our understanding of the meaning of a text on the basis of evidence whose meaning we have already recognized from that very text. Positivism promises to break out of that circularity. According to this tradition, as E. D. Hirsch has argued, the Pauline dictum is reversed: "the spirit killeth, but the letter giveth life." 23

Textual positivism, however, vastly impoverishes our understanding. Within its terms, we cannot move from what the words of a text mean to what an author meant by them. Positivism is also hopelessly equipped to cope in linguistic situations where complete clarity is not possible. A constitution, by definition, speaks from a position of assumed power, and therefore assumes itself able to avoid linguistic obliquity. Literary authors of many kinds, on the contrary, are often obliged or predisposed to adopt linguistic subterfuges. Positivism is, further, massively underequipped to meet the complexities of social existence more generally, since we necessarily inhabit a world in which expressions do not, and cannot, say what they mean. All human forms of communication, in whatever discursive field, say one thing and potentially mean something else. For the most part we are able to forget this, participating in systems of communication that are shored up by deeply ingrained conventional habits of unspoken agreement. Textual interpreters of literary, legal, and biblical texts, whose meanings are subject to powerful competitive forces claiming different meanings, are, however, unable to forget the fragility of the literal sense, and unable to forget the need for interpretative recognition.

By contrast with the textual default positions of revolutionary cultures and their attendant empiricism, literary knowledge must entertain préjugés. Understanding text is dependent on recognition of the text's long prehistory, compacted into the deep coding of genre. At the heart of our reading practice, that is, stands not the revolutionary discovery of the never before known, but rather the reformist recovery of the somehow already known. That recovery always feels new; it has the capacity to bathe the reader in the sense of a freshly discovered perception so as to produce a sense of Dante's "qual maraviglia!" For all that, the discovery itself is better described as a re-cognition, a marvelous uncovering of the immanent and already there. 


\section{IV}

My essay is coming to a close. I began with the representation of recognition in the apparently simple romance Orfeo, in discussion of which I mounted two arguments. In the first place, I sought to change the mind of those who would dismiss such recognitions as "conservative." These recognitions, I argued, were never merely repetitions: they are indeed conservative, retrospective as they are, but the conservatism is self-reforming, since the nonrepetitive recognitions take their participants by reformist surprise. The backward look propels the narrative and its actors forward. In the second place, I argued that, regardless of whether one might, or might not, sympathize with the recognitions of romance, nonrepetitive recognitions are in any case a fundamental characteristic of our interpretive cognition. As readers we deploy re-cognition to take us out of the forest of hermeneutic uncertainty, back home to fresh understanding of the already known. In that forest of uncertainty, after, possibly, many half-recognitions, we fully recognize the "face" of the text, as if under a new moon. Such recognition leads us home.

Let me end, however, with a refined model of the reading practice just articulated. The model so far proposed would have it that, via hermeneutic recognition, we return home to full identification with the text in hand. But that model must fall short, since many (probably all) of us will be unable to identify with, say, the aristocratic, male-centered civilizational model of Orfeo. We can be thrilled by recognizing the text's subtle "face"; we might sympathize with that old face made new. But identify with it? No. A better model, with which I end, might be the frequent topos of the otherworldly recognition in which the embrace of the recognized loved one is in vain. Such recognitions supply us with an even sharper model for our own literary experience: we are immeasurably enlivened by reaching towards the recognized loved one, even as we are painfully deluded by her or his absence.

Dante's Commedia is the great example of a text whose entire narrative of self-knowledge, from dark forest to lucid paradise, is driven by a complex interaction of recognitions and painful leave takings. The recognition registers the profound indebtedness to the figure from the past; the necessity of leave taking registers the often cruel but ineluctable primacy of the present. The overall pattern produces immense, transformative energy for the future. We have observed two such recognitions already in this essay: that of Dante and his teacher Brunetto Latini, and that of Dante and Beatrice. In each case Dante must leave a beloved teacher, whether Brunetto or Virgil, in the half world of shades, even as Dante himself is propelled forward. 
Behind those repeated, enlivening recognitions and painful severances stand classical examples of the failed gaze and/or embrace. These vain embraces derive from an intense desire for identification, but produce a more intense consciousness of loss. Take, for example, the shadow text for the comic, medieval romance with which I began, the classical, tragic myth of Orpheus and Eurydice. Orpheus's longing for his lost wife propels him, in Virgil's narration, even unto and into the underworld, where the beauty of his music enchants the souls from the depths of Hades, the bodiless shades and simulacra lacking light. ${ }^{24}$ Leading Eurydice from the depths, on the very edge of light ("iam luce sub ipsa" [Georgics 4.490]), Orpheus falls victim to the sudden lapse of desire and turns back to seek Eurydice's mutual gaze, only to lose her forever among the umbrae tenues. Both seek vainly to embrace each other, but find only shadows.

Just as Ser Brunetto's recognition of his former pupil Dante occurs in a beautiful half-light (as if "sotto nuova luna"), so too the force of Orpheus's recognition is intensified by occurring on the very edge of light. The other vain embraces of classical literature also occur in unusual lighting: Ulysses recognizes his mother in the half-light of Hades (Odyssey 11.155). Aeneas recognizes the shade of his recently dead wife Creusa in the night scene of Troy under attack, illuminated by lurid and destructive fire (Aeneid 2.752-95). And Anchises recognizes his son Aeneas in Hades as he surveys the souls that will advance to the light ("ad lumen ituras," 6.680). The strange light conditions facilitate, or perhaps produce, the cognitive illumination and emotional power of the meetings: in each the shade informs the full-bodied loved one as to either past or future; and in each case the encounter is highly charged emotionally: Ulysses poignantly tries three times to embrace his mother (Odyssey 11.206); three times does Aeneas attempt to embrace his wife's prophetic shade, which evades him as would a winged dream, "volucri ... simillima somno" (Aeneid 2.794); and three times does Aeneas seek vainly to embrace his father's evanescent shade, "volucri . . . simillima somno" (Aeneid 6.702).

In each case these recognitions bear all the transformative cognitive and emotional force of seeing the past so as to make her old face new. Unlike the recognitions of Sir Orfeo with which we began, however, each of these propels the living into a creative future through a sense of intense loss.

Literary knowledge, in sum, is distinctive; it's dialectical; and it depends as much on what is already known by the reader as on what's new in the text. Without a knowing reader capable of recognizing textual "face," understanding isn't possible. All serious readers are likely to enjoy the 
experience of recognizing textual face sometimes as romance (promising plenitude), sometimes as elegy (premised on loss). Whether promising plenitude or premised on loss, the recognized textual face is not in any way the experience of a radical, Levinasian alterity; on the contrary, our recognition of textual face implies, and realizes, a transformative affective claim we make on that known face.

\section{HARVARD UNIVERSITY}

\section{NOTES}

1 "I recognize the signs of the ancient flame." All citations from the Divine Comedy are drawn from Dante Alighieri, La Divina Commedia, ed. Natalino Sapegno, 3 vols. (Florence: Nuova Italia, 1957). All translations in this essay are mine.

2 "I recognize the traces of the old flame." All citations from the works of Virgil are drawn from Virgil: Eclogues, Georgics, Aeneid, trans. H. Rushton Fairclough, ed. G. P. Goold, Loeb Classical Library 63-64 (Cambridge, MA: Harvard Univ. Press, 1999).

3 My understanding of the nonrepetitivity of recognition, along with much of the argument of this essay, is immensely enriched by Rita Felski, Uses of Literature (Oxford: Blackwell, 2008), chap. 1.

4 All citations from Sir Orfeo are drawn from Middle English Verse Romances, ed. Donald B. Sands (New York: Holt, Reinhart, and Winston, 1966).

5 My central observation in this section is inspired by the project of Hans Georg Gadamer, Truth and Method, trans. Joel Weinsheimer and Donald G. Marshall, 2nd ed. (London: Sheed and Ward, 1989).

6 For a larger address to this issue, see James Simpson, "Derek Brewer's Romance," in A Modern Medievalist: Traditions and Innovations in the Study of Medieval Literature, ed. Charlotte Brewer and Barry Windeatt (forthcoming).

7 W. R. J. Barron, English Medieval Romance (Harlow, Essex: Longman, 1987), 59.

8 For a forceful account of this position, see Julie Orlemanski, "Genre," in A Handbook of

Middle English Studies, ed. Marion Turner (Oxford: Wiley-Blackwell, 2013), 207-12.

9 The argument of this section overlaps with James Simpson, "Faith and Hermeneutics: Pragmatism versus Pragmatism," Journal of Medieval and Early Modern Studies 33, no. 2 (2003): 215-39.

10 Cited from John Donne, "Meditation 17," in Devotions upon Emergent Occasions, ed. Anthony Rapsa (Montreal: McGill-Queen's Univ. Press, 1975), 87.

11 H. P. Grice, "Logic and Conversation," in Speech Acts, vol. 3, Syntax and Semantics, ed. Peter Cole and Jerry L. Morgan (New York: Academic Press, 1975), 41-58.

12 The terms are drawn from J. L. Austin, How to Do Things with Words, ed. J. O. Urmson (Cambridge, MA: Harvard Univ. Press, 1962). For the ways in which these terms absorb authorial intention, see Quentin Skinner, "Motives, Intentions, and the Interpretation of Texts," New Literary History 3, no. 2 (1972): 393-408. It will be clear from this essay that I am an intentionalist, even if I readily recognize that authorial intention is by no means coincident with a text's meaning and possible significance. For a subtle account of the inevitable resurgence of intentionalism, see Seán Burke, The Death and Return of the Author: Criticism and Subjectivity in Barthes, Foucault, and Derrida (Edinburgh: Edinburgh Univ. Press, 1992). 
13 For a broad account of genre and mode, see Alastair Fowler, Kinds of Literature: An Introduction to the Theory of Genres and Modes (Oxford: Clarendon Press, 1982). See also Julie Orlemanski, "Genre."

14 That interpretation is necessarily a circular process is an old point, first stated as such by Friedrich Schleiermacher (1768-1834); see, for example, Friedrich Schleiermacher, Hermeneutics and Criticism and Other Writings, trans. and ed. Andrew Bowie (Cambridge: Cambridge Univ. Press, 1998), 109, 231-32. Very little in the history of interpretation is genuinely new; the point about circularity bears frequent restatement. For the ethical implications of this circularity, see Simpson, "Faith and Hermeneutics," and further references.

15 The example is taken from Stephen C. Levinson, Pragmatics (Cambridge: Cambridge Univ. Press, 1983), 102.

16 Levinson, Pragmatics, 109.

17 For a powerful yet unpersuasive account that literary discourse is not susceptible to the scrutiny we apply to "ordinary" language, see Barbara Herrnstein Smith, On the Margins of Discourse: The Relation of Literature to Language (Chicago: Univ. of Chicago Press, 1978). 18 My image is drawn from http://en.wikipedia.org/wiki/Rabbit\%E2\%80\%93duck_illusion, which supplies further information about the first appearance of this image.

19 The amusing experiment in which viewers directed to look for something miss the anomalous chimpanzee proves the point. See http://www.theinvisiblegorilla.com/gorilla_experiment.html

20 For evangelical reading habits and needs, see James Simpson, Burning to Read: English Fundamentalism and Its Reformation Opponents (Cambridge, MA: The Belknap Press of Harvard Univ. Press, 2007). For evangelicals' polemical necessity of giving absolute priority to text over institution, see chapters 4 and 7 .

21 For the scientific revolution's priority of things and ideas over words, and the correlative dismissal of all figural language, see the excellent essay by Derek Brewer, "Some Observations on the Development of Literalism and Verbal Criticism," Poetica 2 (1974): $7-95$.

22 For recollection in Plato, see, for example, Meno; and in Augustine, Confessions,10.10. 23 E. D. Hirsch, Jr., The Aims of Interpretation (Chicago: Univ. of Chicago Press, 1976), 22.

24 "At cantu commotae Erebi de sedibus imis / umbrae ibant tenues simulacraque luce carentum . .." Georgics, 4.471-2. I thank my friend Alessandro Barchiesi for generous direction to classical accounts of Orpheus. 